\title{
The Value of Epitaph Words Study
}

\author{
Tongxuan Jiang \\ College of Arts, China West Normal University, Nanchong, China \\ Email: jiangtongxuan2006@126.com
}

Received 21 April 2015; accepted 18 May 2015; published 21 May 2015

Copyright (C) 2015 by author and Scientific Research Publishing Inc.

This work is licensed under the Creative Commons Attribution International License (CC BY).

http://creativecommons.org/licenses/by/4.0/

(c) (†) Open Access

\begin{abstract}
Epitaph, as a kind of praising memorial article, its smooth style of writing, complimentary remarks and clever allusions are all leaving rich cultural wealth to the future generations. It is valuable to learn the cultural words in epitaph, especially for the study of subjects such as history, archaeology, philology, cultural history, as well as language and literature. This paper reveals its value depending on the specific materials, hoping to draw more attention to academia.
\end{abstract}

\section{Keywords}

Epitaph, Cultural Words, Value

\section{Introduction}

From time immemorial, China has boasted the tradition of "Merits should be inscribed on Jinshi (monument) or plate of dishes" (Spring and Autumn Annals of Lu, integration of various theories with Taoism as its main part). The study of Jinshi has gone through a long period, too. It began in Han Dynasty, formed in Northern Song Dynasty and reached its heyday in Qin Dynasty.

Epitaph, as a kind of praising memorial article, its smooth style of writing, complimentary remarks and clever allusions are all leaving rich cultural wealth to the future generations. It primarily narrates the lineage and family tradition, the official history, the great achievements, the character styles, the birth and death of the masters. Tablet inscription proves the host's integrity and honesty, represents his intelligence, eulogizes his wisdom and filial piety, and highlights his spirits by giving examples, citing allusions or selecting the master's major events with his performance related to these events. It comments over description. Therefore, paying attention to the ancient memorial literature while collating and researching epitaph for the study of history, archeology, philology, cultural history, language and literature and other disciplines are of great significance.

Culture is symbolic and language is the most crucial token system. Lexicon, as the carrier of culture, has been imprinted with every aspect of social life, mirroring certain cultural phenomenon. Being the construction stuff of language, it also delivers abundant cultural information. Words culture refers to the form and content of words 
imply messages related to politics and economy, ideology, religious beliefs, customs, values, aesthetic taste, way of thinking and habits of presentation during their synthesis, expression and evolution.

\section{The Value of Studying Historical Culture}

China's national culture has a long history and its heritage is of the most complex. Since the so-called culture should focus on history and tradition, ancient literary phrase standing for national annuals and civilization tends to become a vital research area of cultural linguistics. Due to diachronic variation and a lasting interval of time, the primary and basic problem is to deal with semantic annotations, namely exegetical problem.

Language is the symbol and carrier of culture and the characteristics of every national culture will fruit lexically through historic accumulation. A nation's vocabulary system may serve as the most direct and sensitive reflection of its value orientation (Chang, 1998). Hence, through the remains of a period vocabulary, one can detect the cultural appearance and features of this time.

The society of Tang Dynasty is relatively steady and prosperous, yet there still are turbulence and sharp social contradictions. During this era, prevalence of Buddhism and Daoism, acceleration of ethnic integration and reform of the social system brought old funeral customs fresh changes, which were represented in epitaph. Funeral words are important components of Chinese vocabulary, thus a comprehensive study on them can provide a worthy reference for learning China's glossary system and history.

Based on the above considerations, I'd like to choose the epitaph words in the Tang dynasty as research object to explore the social outlook and attribute as well as the people's living convention of Tang dynasty from the perspective of langue.

In describing epitaph, we should try to uncover the various cultural factors contained in these words and the historic background of phrase formation, which of course can broaden the researching areas of lexicology, offering empirical material for discussing Chinese culture words. More crucial, it affords theoretical consultation for studying history, religion, folklore, ideology, etc. The numerous culture-loaded expressions that have been elected would work as first-hand material for historical deliberation of Chinese literacy, education, history, the history of officials , the history of burial, and they are believed to provide historical and cultural researchers with practical assistance.

\section{The Value of Language Study}

From Tang's monumental writing, we can see the systematicness of Chinese lexicon is a huge semantic field. In this field, there are plentiful subfields from different levels, which mainly displays in synonymous polymerization, and cognate and relation polymerization. General and systematic study on the culture-loaded words in the epitaph of Tang Dynasty would consequently supply actually specific, scientific and reliable data to dig deep into vocabulary history of Chinese and to compile Chinese language dictionaries.

\subsection{Syllable Structure Survey}

Both the glossaries and phrase in Tang's inscription can be classified to four categories according to their syllables, namely monosyllable, disyllable, trisyllable and quadrisyllable. By the statistics, disyllable takes a great proportion, accounting for nearly $90 \%$ followed by four-syllable words. Next are three syllables while single syllable comes finally with less than $1 \%$. Many scholars have applied real information to attest the tendency towards disyllablization in Chinese. From the analyzed literary lexicons of the five classes in Tang's epitaph, we may perceive the proportion of polysyllabic words in Tang Dynasty to the whole vocabulary. This is bound up with not only the totally evolutionary trend of Chinese, but also the style of epitaph, the Tang Dynasty's style of wrinting and development and change of word formation.

\subsection{Word-Building Approach Statistics}

Though it belongs to the scope of grammar, word-building impacts immensely on lexis. The difference of morphology in each historic time has distinct effects on the lexical looks of this period. What's more, word-building approach is the basic methods to enrich glossaries and replenish them with new ones. So, in order to understand the words aspect of certain era, one has to inspect the word-formation approaches.

When study the stone writings of Tang Dynasty, we principally learn five kinds of cultural words and analyze 
their totally component disyllable shaping. They have four types of morpheme composition: partially formal, joint, verb-object and subject-predicate. Supplemental type words are not found.

Most of phrases are partially official, dogged by joint type. Verb-object and subject-predicate words are tiny. This is consistent with general trend of Chinese compound formation. The productive style of composed glossaries in the Tang Dynasty's Epitaphs is mostly through monosyllable equipped with culture ideas be used as modifying and finite morpheme and morpheme with cultural terms or two synonymous meaning morphemes. Verb-object components are substantial, but their overall number is still limited.

It is averagely believed that the Chinese vocabulary word formation in Medieval Period is mainly morpheme composite or synthetic. Jiang Shaoyu, a professor of Chinese Department in Peking University, said: "In general, applying lexical extension transformation and sound change to generate fresh ones was highly prolific in ancient times, but after the middle, this method had gradually given way to synthesis. This is a major change in the development of Chinese vocabulary system" (Jiang, 2005). When talked about "the medieval word-building evolution", Pan Yunzhong also put that "since Han Dynasty, composite had, by degrees, become the principal means to yield Chinese neologism” (Pan, 1989). He was a professor of linguistic teaching and researching section in Chinese Department, Sun Yat-sen University. Therefore, investigating the epitaph expressions of Tang Dynasty can provide evidence for studying the history of Chinese language.

\subsection{Showcase of Semantic Fields}

The famous linguist and poet Wang Li once said: "The systematicness of speech sounds and grammar is easy to be realized, but the words of systemic tend to be overlooked by people. We usually consider that words in word list are as dispersive as sand. In fact, they are closely linked" (Wang, 1980). We can see the Chinese vocabulary's schematism from the epitaphs cultural words in the Tang Dynasty, which is mainly manifested in synonymous polymerization and polymerization of the same root. The civilized terms of Tang's inscription are a big semantic field and we are going to analyze and research the following subfields.

\subsubsection{Discussing Semantic Field of Age Lexicons from the Ancient Etiquette and Custom, the} Human Body or Physical Characteristics, Clothing or Flora and Fauna and Historical Stories

Man's age can be classified into infancy, childhood, youth, young, adult, middle-age, elder, etc., among which there is an inferior semantic field standing for minors, covering words such as infancy (including Zainong, Nongzhang, Qinian, Qini, Sheshui, Huaibao, Qiangbao, Duojian, etc.), childhood (containing Xinian, Zhuma, Tiaonian, Tiaoling, Zongri, Zongjiao, Zongfa, Guansui, Guanchu, Guanri, etc.) and juvenile (incorporating Qinian, Qisui, Qiwan, Wanqi, etc.). These words would develop into different synonym semstopc fields, the socalled synonymous polymerization, and most of them below are sharing the same roots. For example, "Tiaonian" and "Tiaoling" are glossaries, which refer to childhood, with "Tiao (means kid's hanging hair)" as their root; "Zongri”, "Zongjiao" and "Zongfa” are based on "Zong”, "Guansui”, "Guanchu”, "Guanri”, "Guannian” and "Tongguan" originated from "Guan" and "Tiao (refers to children who start growing permanent teeth)" is the root of "Tiaori”, “Tiaonian”, “Tiaosui”, “Tiaojie” and "Tiaohua”. They all form a group of cognate words separately.

\subsubsection{Studying Education Words in Semantic Field from the Point of Educational System and Institutions, Women's Civilization, As Well As Education of Confucius Worship And Imperial Examination}

“Keqin or Mengmu (Mencius's mother), Sanqian or Sanxi (triple migrations), Xizhai (resettlement), Zelin (choose neighbors), Jizhu (loom), Duanzhi or Duanji (weaving broken) all refer to Mencius's mother migrated as many as three times in order to select a sound environment for Mencius to study and become excellent); Guoting (across the courtyard, meaning lessons from father or elders); Guixun or Zhenxun, Zhenjie, Zhengui ( lessons and courtesies) form the semantic field of family with children and of education.

"Water Pan, water or pool, bog Bi, Jiaoxiang, Jiaoxu, Xiangxu, Jingshe, Xingtan (almond altar), Huaishi (Huai market), Zhanxu and Piyong are all places for study in the past; Jiaoyu (teaches, meaning teachers in ancient times); Xianggong (selected township examinees)", All these build the semantic field of education system and education institutions.

"Jinshi or Jiake, Liaomao (scholars, candidates who pass the last one exam successfully in the imperial examination system), Mingyang (selection), Eight subjects (total subjects of the imperial examination system); 
Yousu, Hansu, Souyang, Anthologies (They are concrete disciplines)” develop into semantic field of imperial examination education.

\subsubsection{Analyzing Semantic Field of Officials Words from the Point of Apparel Lifestyle, Printed Ribbon Category, Government Offices Etc}

The following are words about clothes culture.

"Clothing crown, clothes chapter, Golden purple ribbon, colorful clothes, Dagon crown, Mianfu, garment tassel, crown skirts, China Dagon, blue shirts, clothes and hood removing: They mean become officers or promotion and constitute the dressing semantic field.

"Crown cicada, crown tassel, Iron crown, China tassel, hanging tassel, hairpin crown" contribute to crown semantic field.

"Waist gold, gentlemen and corona, hairpin petticoats, hairpin group, Zhufu, Zanfu, Zhangfu, crown hairpin, Gun belt, crown belt and Mingyu (singing jade)" construct accessory semantic field.

"Tassel scepter, gown scepter, hairpin scepter, elephant scepter, hairpin like crane, crane bar, Zhigui (hold kyu)" form palm semantic field.

"Canopy cover, crane cover, canopy, China hub, China chariot, phoenix chariot, purple cover" constitute rides semantic field.

Next are official culture loaded terms.

“Turtle button, turtle ribbon, turtle print, turtle chapter, turtle group” construct shape semantic field. "Gold seal, Gold seal and purple ribbon, Silver chapter, Silver seal and green ribbon, silver ribbon, silver print, Silver, copper ink, copper print, copper chapter" make up material semantic field. "Fu crown, green ribbon, green purple, green group, chapter ribbon, tassel fu, Purple fu, purple ribbon" consist of ribbon semantic field. "Amulet bamboo, Tiger amulet, Jiangjie (a kind or red amulet), knot ribbon, pendant turtle, copper amulet, copper fish” compose charm semantic field.

The above subfields work together to comprise a huge semantic field of official cultural vocabularies.

\subsubsection{Study Moral Politics Phrases from Sides of the Officials' Removing People's Sufferings, the} Masses's Appreciating Officer's Virtue-Building, Fairy Tales

"Anren, Phoenix taming, Jiazhi, Pubian, PuMi, Pulun, benevolent climate, ideal politics, Xiange (songs made by strings), Wuxian (blare string), Wuku (five hakama), Fazhi (cutting trifoliate), Maidao (selling knife), Sheep monument, Weeping when looking at tablets, Fighting against the wind to put out fire, song hakama, bamboo horse, Qiumo (paying visits to public miseries), Wujian, Tangyin, Qianwei (curtain)” structure the semantic field of benevolent government.

“Dust retort, morning-drinking sheep, Daoxi (putting one's shoes reversely), Zhijin, Meijin (beautiful brocade), beast floating in river, leave calves, peja calves, easy calves, abandon calves, cooked seafood, cream rain, returning pearl, Qingjin, Hanging bed (means entertaining sages politely), Xunhui or huixun, xunzhai (training birds), scaring phoenix, coming dusk, PyruscalleryanaDecne, sharing wine” establish the semantic field of people eulogizing official's sound politic and indoctrination.

"Colorful chicken, habitat Luan, Xiang luan (a mythical bird like the phoenix), Cross the river, Expelling tiger or other beast, Wind driving away beast, Beast training, Animal crossing, Milk tiger, Moving locust, Avoiding locust, Locust flying, Locust evolution, Qun fish, Coming phoenix, Milk pheasant, being indifferent to disaster hail, locust-avoiding places, Plague locust, Insects, disaster wind, locust provoking” form mythologically semantic field of virtue-building.

\subsubsection{Discussing Expressions about Death from the Aspects of Euphemistic Death, Taboo Psychology and Metaphor Words}

"Dream Joan or Joan dream, Zhongtang, returning, Qiyang (abandonment), Donating world, Juqing (tilting), Qishouzu (becoming brother), Jizhen (becoming true), Yanran (sudden), Zhukuang” compose semantic field of euphemistic death words.

"Bulu, Panhao (climbing and then crying), belong to the whole, donating life, donating death, returning the stillness, totally change, great and final period, Hansui, Gouhuo (suffering from disaster), Shezhao, Cangcu” form the semantic field of evading death.

"Jidai (that world), tired of world" consist of the semantic filed of psychological taboo words. 
"Becoming crane, closing the eyes, removing harps, dew, Youtai (going sightseeing in Mount. Tai)” form the semantic field of metaphor death loaded words.

Leaving this world naturally means putting aside everything of the world, including glory and wealth. Therefore, people also build semantic field to imply death in this way, contributing official trip, house, Zhujing, Pandian, Zhaodai (the era of political correctness), Cabinet, curtains, Panyang, Yuanshe, purple silk, wealth, clothing of Han dynasty and vanity fair.

What's more, the roots of these vocabularies are words that boast cultural implication. Studying these roots is of great beneficial for us to accurately reveal the cultural meaning of these phrases, understand the relationship between terms and their culture while demonstrating the semantic systems of literary words. To explore the etymology of epitaph expressions, examine the structure characteristics of culture loaded words, analyze their building foundation and clear their semantic evolution can provide valuable reference for the theoretical study of lexicology. It also has crucially theoretical significance for enriching and bettering vocabulary especially ancient Chinese vocabulary.

Yunlu Wang concluded the study of mediaeval and ancient Chinese vocabulary (Chinese in Northern and Southern, Sui and Tang Dynasties) that "many of the medieval and ancient Chinese researchers in the early stage were concentrating in specific words, especially in the explaining of special and difficult phrases. They rarely probed theoretical issues such as the rules of word formation, development and evolution, the inner links between lexicons, and the lexical meaning system” (Wang, 2010). Our systematic analyses of Tang's sculpture words are an attempt to expose features and laws of this system. The medieval ancient phrases would not be hard to grasp if the characteristics and rules of every kind of word were lucidly figured out,

\section{The Value of Literature Arrangement}

Investigating and interpreting knotty expressions in epitaphs fundamentally guarantee the literature interpretation and arrangement of stone inscription from the aspect of language and characters, making it more accurate, scientific, while offering reliable as well as scientifically applicable epitaph materials for learning other literature and history subjects.

Researching on the words of epitaph culture in Tang dynasty depends on the collection and review of the Tang's engravings. Epitaph survey and analysis can, in return, correct the mistakes in epitaph character interpretation, enabling the organization more precise and suitable.

\subsection{Text Misreading}

Interpreting tablets and scientifically tidying stone inscriptions are the premises of utilizing epitaph documents to conducting various discipline studies. And one of the difficulties in tablet interpretation is illusion, whose core is culture. Therefore, learning literary terms presents positive significance to the scientific arrangement of stone inscriptions.

It is effortless to account for texts and seize their contents with common stories; but to understand obscure and rarely employed allusions is not that easy. Furthermore, misunderstandings of substance will naturally affect the correct interpretation of inscription texts. Barriers like stone-face stripping, variants and popular usage of characters, wrong written and ancient writing remains can be caught now and then. What's more, text misreading as well as punctuation disorder are quite serious in sorted inscriptions literature.

\subsection{Allusions and Epitaph Explanation}

Epitaph paper prevailingly describes life stories of the masters, praises their performance and lineage genealogy. It is a kind of important literature with history properties, and has multifarious research worth. Its style of writing is mainly self-description involves both discussion and praise, most of them quote many allusions (Mao, 2009).

Generally, it is effortless to account for texts and seize their contents with common stories; but to understand obscure and rarely employed allusions is not that easy. Furthermore, misunderstandings of substance will naturally affect the correct interpretation of inscription texts. Barriers like stone-face stripping, variants and popular usage of characters, wrong written and ancient writing remains can be caught now and then.

We took unclear relation between phrases and incorrect interpretation brought by illusion misunderstanding in Tang's epitaph explanation as examples to analyze the text misreading while filling the gap left by departure of 
the characters, presenting valuable reference for finding scientific methods to arrange stone documents, and extracting their internal rules.

\section{Conclusion}

In short, only through proper comprehension of the origin and content of the mass stories in Tang's epitaphs can we accurately interpret monumental writings. And only correct text can help in figuring out the real meaning. More importantly, only by offering neatened documents and ensuring their scientific nature can we make use of them to engage in multidisciplinary research in the field of literature and history, and play their due roles. Flawed interpretation and arrangement may be misleading to researchers, and even cause false research conclusion.

\section{Funding}

The paper is supported by "The Fundamental Research Funds for the Central Universities" of SWU (No: SWU1409317) and “The Startup Funds for Doctors” of China West Normal University (No: 14E010).

\section{References}

Chang, J. Y. (1998). Chinese Vocabulary and Culture. Beijing: Peking University Press.

Jiang, S. Y. (2005). Outline of Ancient Chinese Vocabulary. Beijing: The Commercial Press.

Mao, Y. M. (2009). General Theory of Stone Inscription. Bejing: Zhonghua Book Company.

Pan, Y. Z. (1989). History Outline of Chinese Vocabulary. Shanghai: Shanghai Ancient Books Publishing House.

Wang, L. (1980). Chinese Language History. Beijing: Zhonghua Book Company.

Wang, Y. L. (2010). Medieval Chinese Vocabulary History. Beijing: The Commercial Press. 